\title{
Clinical Features of the Intermittent Rhythmic Delta Activity and Periodic Patterns in Electroencephalogram
}

\author{
Rodriguez Rivera Sofia Lucila*1, Perez Ramirez ${ }^{1}$ and Jose Mariel ${ }^{2}$ \\ ${ }^{1}$ Departament of Pediatric Neurology; Centro Medico Nacional La Raza, Mexico \\ ${ }^{2}$ Departament of Pediatric Neurology; Hospital Infantil de México Federico Gómez, Mexico
}

Received: May 25, 2018; Published: May 31, 2018

*Corresponding author: Sofia Lucila Rodriguez Rivera, Department of Pediatric Neurology, Centro Medico Nacional La Raza; Calzada Vallejo S/N, Col. La Raza, Delegacion Azcapotzalco, Ciudad de Mexico; Mexico

\begin{abstract}
The importance of intermittent delta activity and periodic patterns in the electroencephalogram has intrigued neurophysiologists for decades. The clinical interpretations varied from nonspecific to suggested structural metabolic behavior, infectious and even epilepsy [1]. The most frequent clinical features were determined by clinical history of children with intermittent rhythmic delta activity and periodic patterns (January 2013-June 2017). Total 16 patients, Female $9(56 \%)$. Periodic patterns: 25\% ( $\mathrm{n}=4$ ) PLEDs, 13\% ( $\mathrm{n}=2$ ) BiPLEDs and 6\% (n=1) GPEDs. Intermittent rhythmic delta activity: 50\% $(n=8)$ FIRDAs and 6\% $(n=1)$ OIRDAs. The most frequent causes of PLEDs were infectious and tumoral in $12.5 \%(\mathrm{n}=2)$ respectively. Tumor causes were the most frequent cause of FIRDAs $31 \%(\mathrm{n}=5)$, then neuroinfection $12.5 \%(\mathrm{n}=2)$ and vascular $6 \%(\mathrm{n}=1)$. The most frequent periodic pattern was PLEDs and the most frequent intermittent rhythmic delta activity was FIRDAs, with more common etiologies tumor and neuroinfection, which is similar to the international literature $[2,3]$.
\end{abstract}

Keywords: Intermittent rhythmic delta activity; Periodic patterns

\section{Introduction}

The importance of intermittent delta activity and periodic patterns in the electroencephalogram has intrigued neurophysiologists for decades. Clinical interpretations varied from nonspecific to suggested structural, infectious, metabolic behavior and even epilepsy [1,4-7].

\section{Methods}

The patients were interviewed, the purpose of the study was explained to them and they signed an informed consent letter. The most frequent clinical features were determined by clinical history and neurological examination of infant patients with intermittent rhythmic delta activity and periodic patterns in the electroencephalogram, in Hospital Infantil de México "Federico Gómez", Mexico City, in the period of January 2013 to June 2017. The results obtained were compared with that reported by the World Literature.

\section{Results}

During the period from January 2013 to June 2017, a total of 16 patients with a diagnosis of intermittent rhythmic delta activity and periodic electroencephalogram patterns were reported. Predomi nance of female gender 9 patients (56\%). Of the periodic patterns,
25\% $(\mathrm{n}=4)$ corresponded to PLEDs, $13 \%(\mathrm{n}=2)$ BiPLEDs and $6 \%$ $(\mathrm{n}=1)$ GPEDs. Of the intermittent rhythmic delta activity, 50\% (n = 8) corresponded to FIRDAs and 6\% $(n=1)$ OIRDAs. Infectious and tumoral causes were the most frequent cause of PLEDs, presenting $12.5 \%(n=2)$ respectively. Tumor causes were the most frequent cause of FIRDAs, presenting in 31\% ( $n=5)$, followed by neuroinfection in $12.5 \%(\mathrm{n}=2)$ and vascular in $6 \%(\mathrm{n}=1)$.

\section{Discussion}

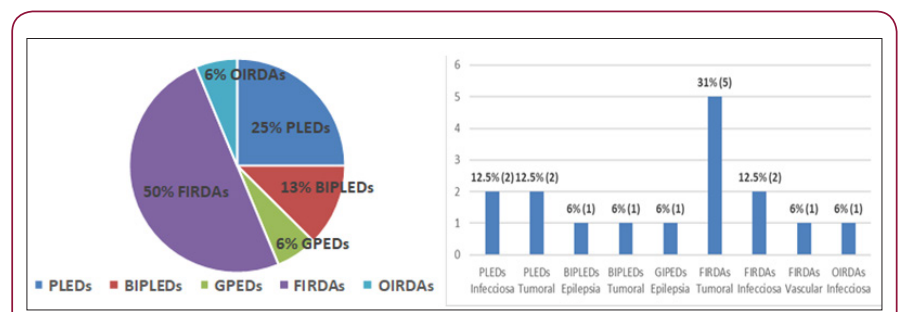

Figure 1: Frequency and etiology in intermittent rhythmic delta activity and periodic patterns in the electroencephalogram (A and B).

The most frequent periodic pattern was PLEDs and the most frequent intermittent rhythmic delta activity was FIRDAs, with 
more common etiologies tumor and neuroinfection, which is similar to the international literature [2,3,8-10] (Figures 1\& 2).
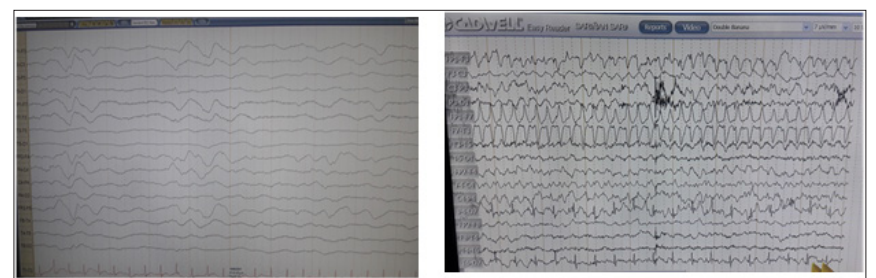

Figure 2: Intermittent rhythmic delta activity and periodic patterns in the electroencephalogram (A and B).

\section{References}

1. Di Gennaro G, Quarato PP, Onorati P, Manfredi M, Esposito V, et al. (2003) Localizing significance of temporal intermittent rhythmic delta activity (TIRDA) in drug-resistant focal epilepsy. Clin Neurophysiol 114: 70-78.

2. Riviello J, Foley C (1992) The epileptiform significance of intermittent rhythmic delta activity in childhood. J Child Neurol 7(2): 156.

3. de la Paz D, Brenner R (1981) Bilateral independent periodic lateralized epileptiform discharges: clinical significance. Arch Neurol 38(11): 713.
4. Gullapalli D, Fountain NB (2003) Clinical correlation of occipital intermittent rhythmic delta activity. J Clin Neurophysiol 20(1): 35-41.

5. Garcia-Morales I, Garcia MT, Galan-Davila L, Gomez-Escalonilla C, Saiz-Diaz R, et al. (2002) Periodic lateralized epileptiform discharges: etiology, clinical aspects, seizures, and evolution in 130 patients. J Clin Neurophysiol 19: 172-177.

6. Fitzpatrick W, Lowry N (2007) PLEDS: clinical correlates. Can J Neurol Sci 34(4): 443-450.

7. Raroque HG, Purdy P (1995) Lesion localization in periodic lateralized epileptiform discharges: gray or white matter. Epilepsia 36(1): 58-62.

8. Alehan F, Watemberg N (2001) Clinical and laboratory correlates of frontal intermittent rhythmic delta activity (FIRDA). Dementia 9: 13.

9. Walser H, Isler H (1982) Frontal intermittent rhythmic delta activity, impairment of consciousness and migraine. Headache J Head Face Pain 22(2): 74-80.

10. Watemberg N, Linder I, Dabby R, Blumkin L, Lerman-Sagie T (2007) Clinical correlates of occipital intermittent rhythmic delta activity (OIRDA) in children. Epilepsia 48: 330-334.

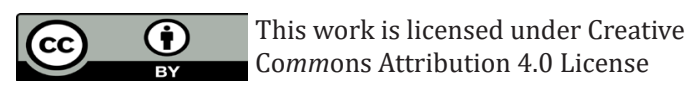

Submission Link: https://biomedres.us/submit-manuscript.php

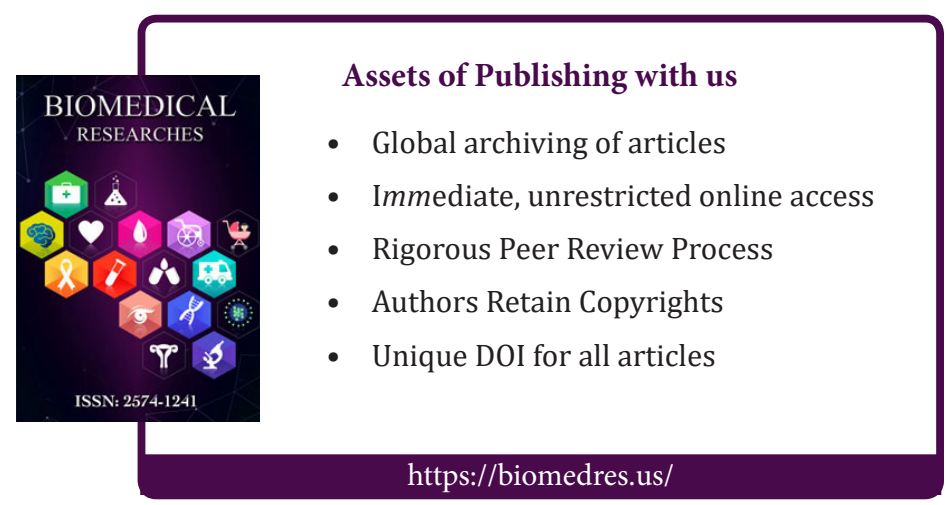

